symptoms, of the nature and import of which he is profoundly ignorant, to give powerful drugs, in nine cases out of ten neither suitable in dose, in their application to the disease itself, nor to the constitution of the patient.

Opium, mercury, and iodine, and some drastic cathartic pills, are the most frequent and favorite medicines dispensed to all applicants; and we scarcely know whether more mischief is done by the indiscriminate administration of these purging pills to adult dyspeptics, of soothing syrups and other forms of opiates to infants and young children, or of calomel and blue pill, in the midst of the scrofulous and squalid population, from the ranks of which their customers are chiefly derived.

It is especially from the indiscriminate use of mercurials and opiates not only that a great sacrifice of infant life takes place in towns, but also a very material deterioration of the powers of the system and of the constitution in after life. Medicines of the former class-mercurials-are administered to a great extent in the families of both rich and poorin the one case by domestic prescription, in the other by the direction of the druggist or his shop-boy. The latter are the great resource of indolent nurses and careless or imprudent mothers, to quiet what are termed fretful infants; and in like manner, and with the same views, are dispensed by the druggist, who takes his cue from the desire for rest expressed by the mother; and regardless of the well-being of the infant, as well as ignorant of the methods of providing for it, all parties conspire to mask the disease under which it is laboring, by stupifying its sensibility, until the foundation for incurable organic change is laid, and it either dies or grows up weakly, and a burden to itself and all connected with it.

We fear that there is little probability of reaching mischiefs such as these either by statistical inquiries or legal enactments. Still the attempt should be made; and while, by the attainment of that measure of information which we can come at, we may be able to instruct the public mind, now deeply in ignorance upon these matters, and to warn parents and friends of the manifold evils and dangers of the practices now so extensively followed, by proper legal provision making druggists and others responsible for their homicidal acts, a preventive check might to some extent be placed upon the evil. Were a sufficient case also made out, through the RegistrarGeneral's office, there would be a clear and decided call for legislative interference, which neither Parliament nor the Government could well refrain to attend to. It is, therefore, much to be wished that all those engaged in the practice of medicine should comply with the expressed wishes of the RegistrarGeneral, by forwarding, in every instance, a faithful record of the fatal cases occurring in their practice.
The information thus collected would be available, in many ways, as a valuable contribution to statistics, as tending to define our views on the causes of disease in general, and to suggest practical rules for the prevention of many diseases which now press heavily on different classes of the manufacturing population, or materially interfere with the comfort and prosperity of the inhabitants of some districts of the country; while, by showing the effect of the too frequent neglect of proper medical treatment among the chil. dren of the poor, it will indirectly afford that evidence of the mischiefs resulting from the exhibition of powerful medicines by illegal and unqualified persons, which is required to compel the attention of those in authority to the reiterated representations made to them on this subject.

\section{CONTAGIOUSNESS OF PUERPERAL FEVER}

The readers of this Journal no doubt recollect a most important letter from Mr. Storrs (Provincial Journal, April 23, 1842), showing the close connection between erysipelas and puerperal fever, and the great risk there is of producing the latter disease by infection or contagion from erysipelatous patients. The subject is one of such extreme importance, not only as regards the lives of the patients, but also the character and prospects of the medical attendant, that it cannot be investigated too frequently or too searchingly; and wo are glad to find a paper by Dr. 0 . W. Holmes, in an American contemporary, in which the contagiousness of puerperal fever is fully borne out.

\section{THE WATER-CURE AT MALVERN.}

\section{TO THE EDITORS OF THE PROVINCIAL MEDICAL JOURNAL.}

Gentremen, - In one of your late Journals there is a lengthened paper inserted, which purports to be the correct account of a case of disease treated by myself in the first instance, and subsequently by Dr. Hastings, of Worcester, whose comments are appended to it. As it contains statements and remarks that are libellous, and highly defamatory of my professional character, and, moreover, are utterly devoid of truth, I claim the right of reply in the journal which gave them publicity.

The subject of the case, Probart, was a carrier between this place and Worcester, and notoriously addicted for a great many years past to hard drinking, which had, indeed, reduced him to poverty. He was sixty-four years old, and had suffered from gout for above thirty years; he had also other complaints, with great difficulty of breathing, and considerable disease of the heart, of which there was every symptom. He applied to me twelve months ago, and I treated him without any remuneration. He was only a fortnight under my care, and his improvement in every respect was so great that it made a sensation in the village and neighbourhood. He remained well for three months, attending to his ordinary occupation, and, as his son has told me, to the day of his death spoke 
of the "water-doctor having done him more good than any one." From that time, nearly twelve months ago, I refused to have anything to do with him; he had returned to his old drinking propensities, of the certain results of which he was warned by myself and by others, among them by Mr. Trent, a gentleman of the highest respectability residing near this place; to whose warning Probart replied, " that if it killed him he could not leave off the drink." During these months I frequently spoke to him in the street. On one occasion he said he was taking acid and laudanum in large quantities, by the advice of a kind lady." Later still I saw him with a swelled and ghastly face, and all the appearance of a dying man. Inquiring the cause, he replied, "They gave me a deal of mercury, and did not tell me; I went out, and got wet and cold, and my gums and throat were so sore and swelled that I could not swallow for upwards of a week. I fecl all rotting inside." He was soon laid up again, and Dr. Hastings and Mr. Addison went on with their treatment. Here, then, is a poor man who had been destroying his constitution for years by every kind of intemperance, subjected in a careless manner to the destructive effects of mercury, which ended, as every scientific medical practitioner might have anticipated in such a case, in dropsy, utter destruction of the constitution, and death. And yet Dr. Hastings, because it serves a certain purpose, has the effrontery to assert that a short treatment by myself, nearly twelve months previous, followed by comparative health for three months, was the cause of his death, and not, as is evidently the case, the result of the poor man's own imprudence, assisted by the most unjustifiable and injudicious treatment on the part of Dr. Hastings. God forbid that I should for a moment harbour the thought, or suppose this to be more than error on the part of his medical attendants. However, Sir Astley Cooper says (in the " Lancet," A pril, 1824), "Mercury is by no means an unfrequent cause of dropsy," and a host of medical writers enumerated by Dr.Copland in his " Dictionary of Practical Medicine," art. Disease of the Heart, say that "long-continued intemperance causes disease of the heart."

I have the honor to be, Gentlemen,

Yours obediently,

James Wilson.

Great Malvern, Aug. 14, 1843.

[The passages which we have omitted are so utterly irrelevant to the case of Probart, are so personal and libellous in their character, and partake so much of the nature of an empirical advertisement, that we cannot think of occupying our pages with them. In the individual instance of Probart the question is purely one of credibility between Dr. Hastings and Mr. Addison, two gentlemen of unblemished reputation and the highest professional character, on the one hand, and Dr. Wilson on the other. In a postscript to his letter, which we subjoin, Dr. Wilson requests the insertion of a favorable case as a set-off to the case of Probart. We would, however, observe that Dr. Kinglake could have produced many such, but the question is not whether gout may be occasionally cured under the cold-water treatment, but whether this treatment can be safely had recourse to. To this subject, however, we purpose to return on another occasion.]
P.S.-I may also in fairness request the insertion of the following authenticated case as a set-off to the one you have published, which was intended, and most likely will injure my professional reputation and interests :-

\section{CASE OF GOUT.}

Malvern, Sept. 16, 1842.

My Dear Sir,-I cannot take leave of Malvern without again expressing to you my thanks for the encouragement you gave me to try the effect of the water-cure as you practise it, and for your kind attention to me during the time I have undergone the treatment. I have now gone through the perspiring process, followed by the bath, fifty times, with the other parts of the treatment; I found them anything but disagreeable, indeed I may say quite the reverse, and they have been most beneficial to me. During nine months before I came here I was never able to move without my crutches, and a great part of that nine months I passed in my bed or on the sofa. My nights were restless, my pulse high, and my tongue charged. I am now turned sixty-three years of age, and have been subject to the gout more than forty years; I paid little attention to it for the first twenty years, and as soon as the fit was over I never missed taking my wine daily. My knees, hands, and other parts were so crippled that I had made up my mind to pass the rest of my days in my arm-chair or bed, or to hobble about with my crutches. The effect of the treatment has so ameliorated my situation, that I can now go up and down stairs with ease and comfort without a stick, and the other day walked half a mile on the high road. I frequently ride on horseback four hours a-day, and my general health, I thank God, is as well as ever it was in my life; I sleep well, my appetite is good, I can use my arms freely, and tie my neckcloth-a thing I had not been able to do for years; in fact, I feel myself comfortable and independent. Had I come here a year ago, and undergone the same process, I have no doubt but I should have saved my left knee from being contracted; as it is, I am contented to walk a little lame, and shall be too happy to remain in the same state $I$ am in at present for the rest of my days. Pray excuse this long scrawl, as I know you have not a minute to spare, and believe me,

\section{My dear Sir,} Yours most truly,

\section{Park-hall, Epping, Essex.}

$$
\text { T. C. Marsh. }
$$

\section{6, Rue Matignon, Paris.}

P.S.-It is now nearly twelve months since this letter was written; and a few weeks ago Admiral Beauman received a letter from Mr. Marsh, in which he stated that " he is still in perfect health, with every prospect of continuing so."-J. W.

\section{PROPOSED TEST OF THE COLD-WATER CURE.}

TO THE BDITORS OF THE PROVINCLAL MEDICAX JOURNAL.

Gentlemen,-It is, I believe, alleged that the cold-water treatment, so called, is sufficient to cure all curable diseases, and that medicines are, therefore, useless, if not injurious. It occurs to me that it 